\title{
Designing Android Based Augmented Reality Location-Based Service Application
}

\author{
Alim Hardiansyah \\ Department of Informatics Engineering \\ Institut Sains dan Teknologi Al-Kamal \\ Email:alimhardinsyah@ista.ac.id
}

\begin{abstract}
Android is an operating system for Linux based smartphone. Android provides an open platform for the developers to create their own application. The most developed and used application now is location-based application. This application gives personalization service for mobile device user and is customized to their location. Location-based service also gives an opportunity for the developers to develop and increase the value of service. One of the technologies that could be combined with location-based application is augmented reality. Augmented reality combines the virtual world with the real one. By the assistance of augmented reality, our surrounding environment could interact in digital form. Information of objects and environment surround us could be added to the augmented reality system and presented. Based on the background, the writers tried to implement those technologies on now rapidly developing android application as a final project to achieve bachelor degree in Department of Informatics Engineering, Faculty of Information Technology and Visual Communication, Al Kamal Science and Technology Institute. This application could be functioned to locate school by using location-based service technology with the assistance of navigational applications such as Waze and Google Maps, in form of live direction process through the smartphone.
\end{abstract}

Keywords: Augmented Reality, Location-based Service

\section{INTRODUCTION}

Its educational quality is highly variated from having luxurious building to the simple ones. Along with schools built by the government, there are many schools built by privates. Not everyone in society could be in pace with rapidly developing education. Sometimes they find it difficult to access on information, such as information about senior high schools and their location in Tangerang city. By the fact of rapidly developing information and communication technology, the writers had done a research to solve those problems by creating an application that uses the augmented reality technology and location-based service. The application could give the information and locations of senior high schools in Tangerang on android platform based mobile devices.

Mobile devices with android platform are now rapidly developing. Almost everyone has this device. Android is an operating system for Linux based smartphone. Android provides an open platform for the developers to create their own application. The most developed and used application now is location-based application. This application gives personalization service for mobile device user and is customized to their location. Location-based service also gives an opportunity for the developers to develop and increase the value of service.
One of the technologies that could be combined with location-based application is augmented reality. Augmented reality combines the virtual world with the real one. By the assistance of augmented reality, our surrounding environment could interact in digital form. Information of objects and environment surround us could be added to the augmented reality system and presented. With an application that combines augmented reality technology and location-based service, hopefully the society could be helped in accessing information about senior high schools in Tangerang city.

The research problems are:

1. How to use augmented reality technology on android?

2. How to acquire the latitudes and longitudes of senior high schools in Tangerang city?

The research aims are:

1. To create an application for senior high schools in Tangerang city.

2. To use the latitudes and longitudes of senior high schools in Tangerang city accurately as the markers in application.

To be able to illustrate clearly and to simplify the existing problems, the writers had restricted the problems as follows:

1. Data in the application was restricted to senior high schools in Tangerang city. 
2. Data in the application such as locations and information were restricted to be presented in google maps.

3. The application was developed with android basis.

\section{RESEARCH METHOD}

To acquire a systematic procedure and accurate data standard in this final project assignment, the writers used some methods that could help until the data could be gathered as follows. Literature Study To be able to solve the problems and enrich the materials related to research methods as well as explanation, the writers had studied the materials such as books at the library and the other supporting materials. Observation After the data required in the literature study had been acquired, the data then gathered and analyzed until it leads to a right conclusion.System Analysis It was done by parting, differing, and choosing the materials to be re-classified according to the particular criteria and then by seeking their relations and interpreting the meanings.

Application Design It was including about how the content to be presented and sent to the final user so that it could be accessed on android based smartphone.Coding is writing instructions in particular programming language to make a program on computer. System Implementation A process to place a new information system in existing operating system so that it could be used. System Testing In the process of software development, it was done by seeking and minimizing the bugs in the system, so that it could work well as can be expected. In this research, the testing was done by using a black box and questionnaire.

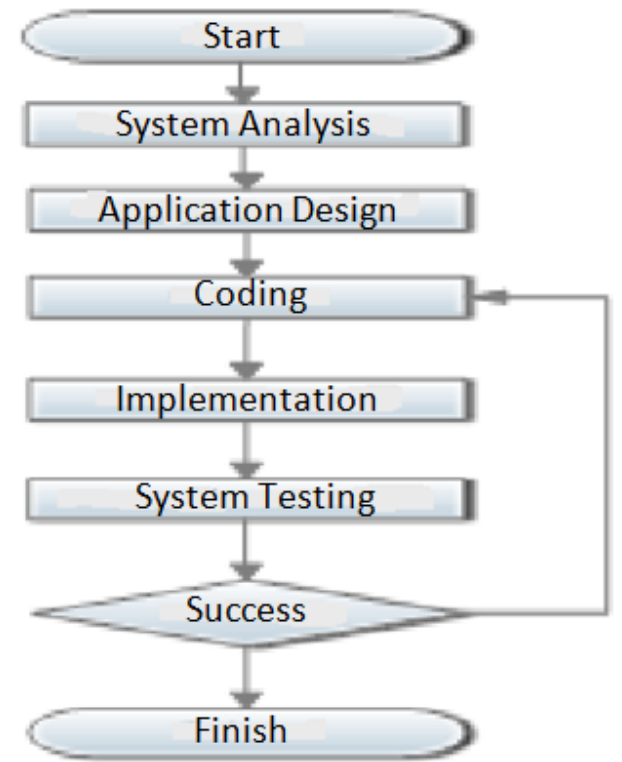

Figure 1. Software Development

\section{ANALYSIS AND EXPLANATION}

\subsection{System to be Developed}

In this writing, the writers are going to make an application with augmented reality or added reality using location-based service that functioned to show the location of state or private senior high school in Tangerang. This application was built by using internet-based platform layar augmented reality. [2]

To save the data of locations, information, and distances to schools, the writers made a database on web hosting. This application would show dots or points of interest that shows the position of schools in Tangerang. The user could adjust the point of interest's search range in kilometer scale from user's position. [5] Every point of interest could be selected to see the information of address and how many kilometers is the distance between school and user.

\subsection{Requirement Analysis}

Requirement analysis is a stage or process to identify about what is needed in designing an application, to determine the specification of needs to build the application that was already planned. In this case, the writers tried to do a requirement analysis grouped to three part: hardware analysis, software analysis, and user analysis. [3]

\subsubsection{Hardware Analysis}

Hardware analysis is an activity to analyze what hardware needed to build the application, and in this case is the development of Augmented Reality Location-based Service Application for senior high schools in Tangerang city. The writers were using laptop device A45V with the specification as follows:Processor Core i3 - 2370M 2.4 GHz, RAM 2 GB, VGA NVIDIA 2GB Geforce 610M, Harddisk 500GB

\subsubsection{Software Analysis}

Specifications of software used in the development of this application are as follows: Eclipse, Xampp, Layar, Notepad++, Photoscape

\subsection{System Design}

System design is an activity of determining stages that would be done in developing an application [1]. This is important in application development to make sure a structured development process, in this case is the process of developing Augmented Reality Location-based Service Application for senior high schools in Tangerang city.

\subsubsection{Menu Design}

Figure 2 illustrates the design of application menu. 


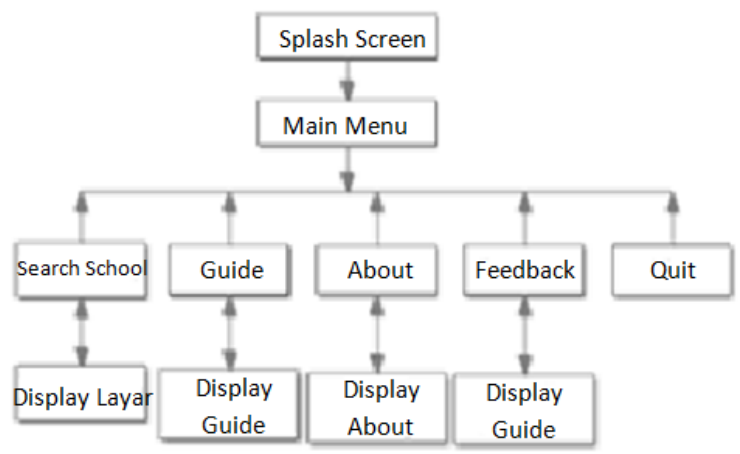

Figure 2. Menu Design

Information:

1. When user opens the application it will display Splash Screen before the main menu displayed.

2. When Main Menu displayed, there will be five menu

3. Search School functioned to search the information about schools

4. Guide functioned to display application use guide such as conditions to run the application and how to run the application.

5. About functioned to display brief profile of writers and the description of application.

6. Feedback functioned as interactive media between user and developer of application to deliver any critics and suggestions.

7. Quit functioned to close the application.

3.3.2 Use Case Diagram

Figure 3 illustrates the use case diagram.

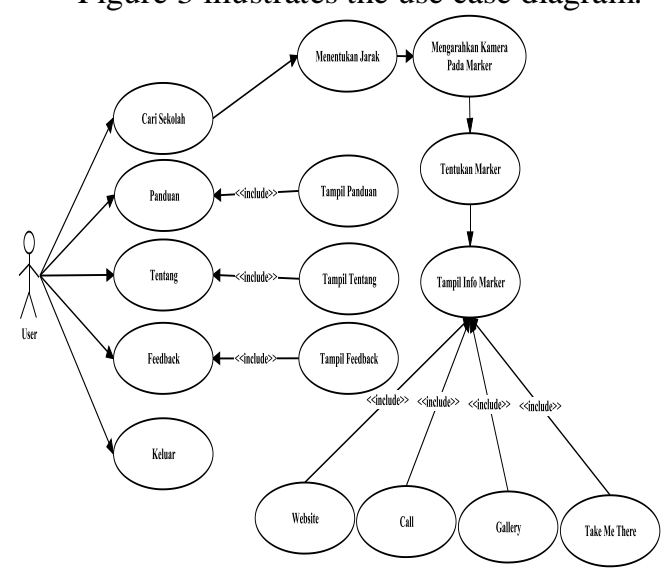

Figure 3. Use Case Diagram

Information:

Table 1. Actor Definition

No Actor Description

1 User Person that use the application

Table 2. Definitions of Use Case

\begin{tabular}{llll} 
No & Actor & \multicolumn{2}{c}{ Description } \\
\hline 1 & Search School & Is a process to search on
\end{tabular}

\begin{tabular}{lll}
\hline No & Actor & \multicolumn{1}{c}{ Description } \\
\hline & & schools \\
& Guide & Is a process to see the guide \\
3 & About & Is a process to see about \\
4 & Feedback & $\begin{array}{l}\text { Is a feedback process to see } \\
\text { feedback } \\
5\end{array}$ \\
& Quit & $\begin{array}{l}\text { Is a process to quit from the } \\
\text { application }\end{array}$
\end{tabular}

\subsubsection{Activity Diagram}

These are the activity diagrams of the application.

1. Activity Diagram of Search Schools

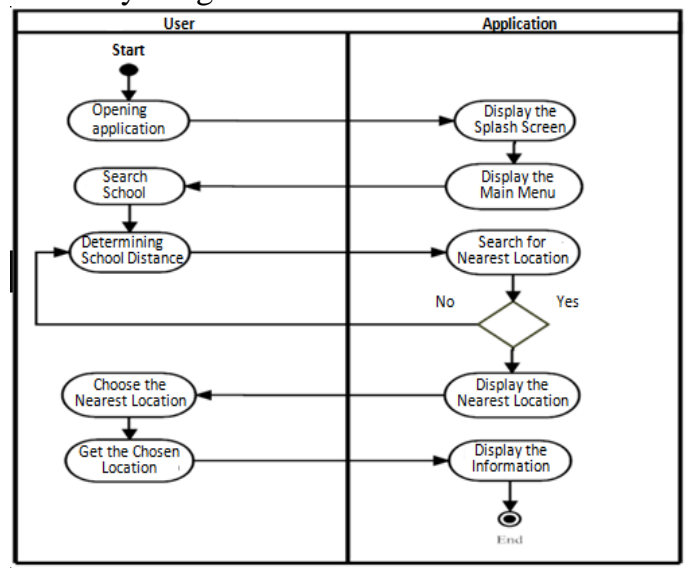

Figure 4. Activity Diagram of Search Schools

Activity diagram above is the activity that will happen when the user chooses Search School menu.

2. Activity Diagram of Guide

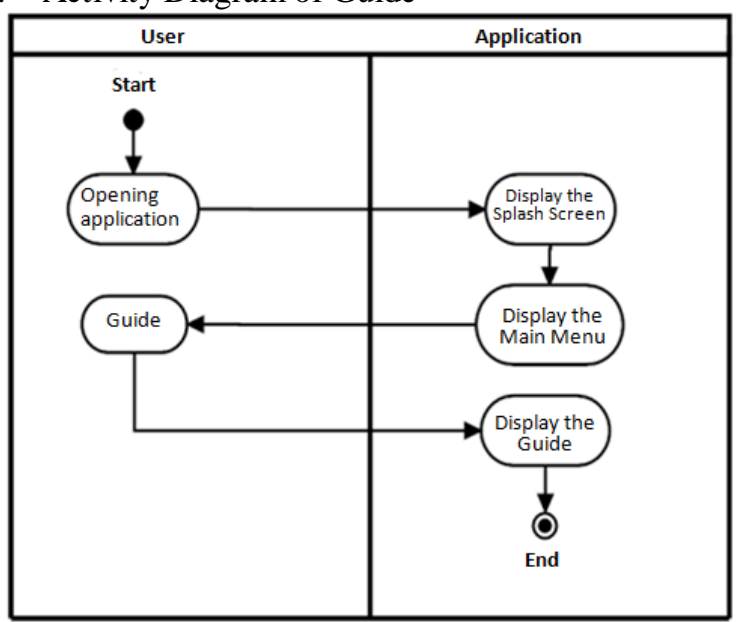

Figure 5. Activity Diagram of Guide

Activity diagram above is the activity that will happen when the user chooses Guide menu.

3. Activity Diagram of About 


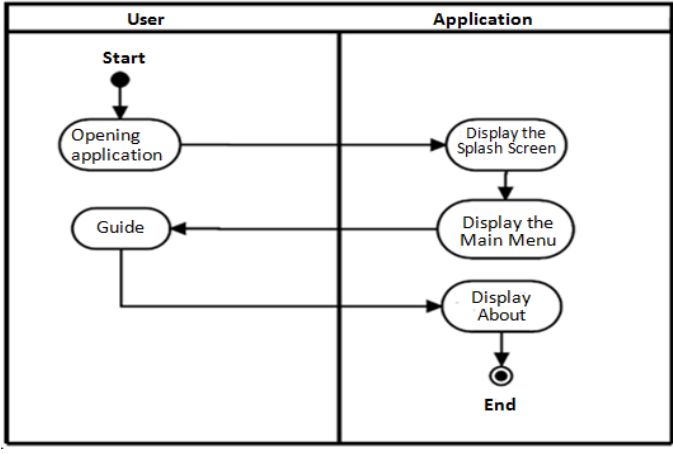

Figure 6. Activity Diagram of About

Activity diagram above is the activity that will happen when the user chooses About menu.

4. Activity Diagram of Feedback

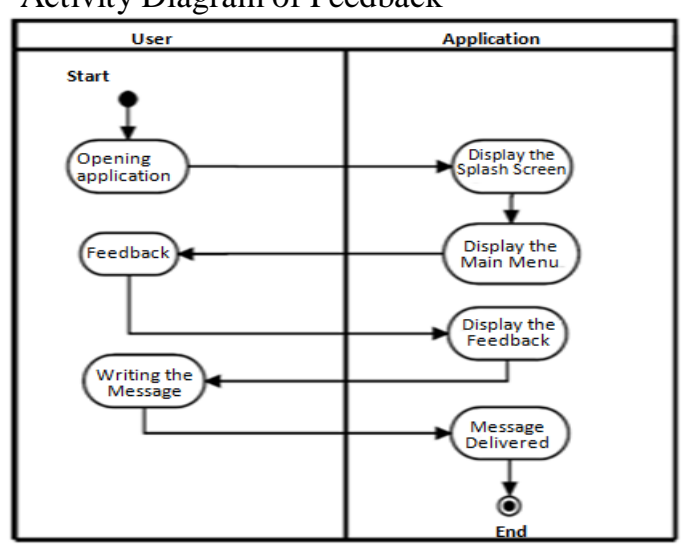

Figure 7. Activity Diagram of Feedback

Activity diagram above is the activity that will happen when the user chooses Feedback menu.

5. Activity Diagram of Quit

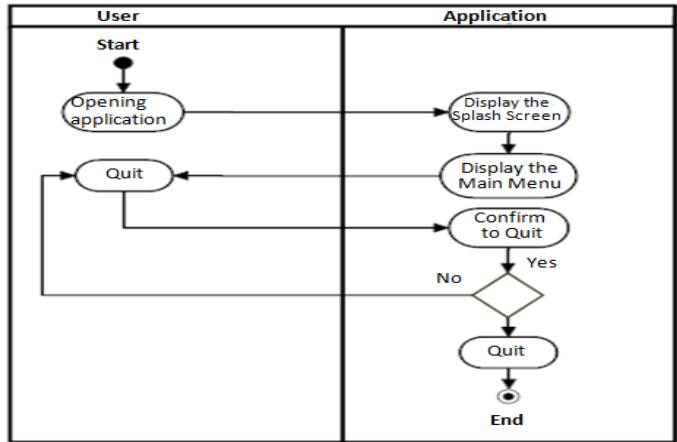

Figure 8. Activity Diagram of Quit

Activity diagram above is the activity that will happen when the user chooses Quit menu.

\subsubsection{Sequence Diagram}

These are the sequence diagrams of the application.

1. Sequence Diagram of Search Schools

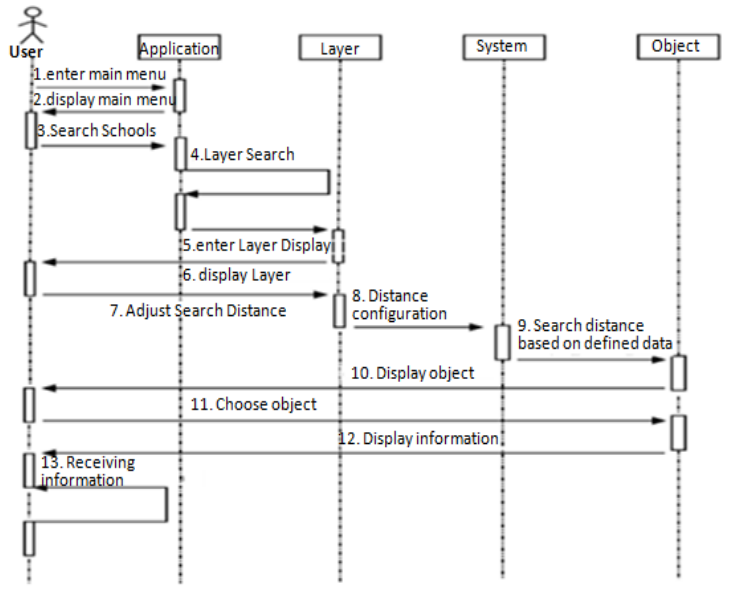

Figure 9. Sequence Diagram of Search School

Sequence Diagram above is the process that will be happen when the user choose Search School menu from the main menu and then the layar application will be integrated with the main application and begin to determine the radial distance in searching schools.

2. Sequence Diagram of Guide

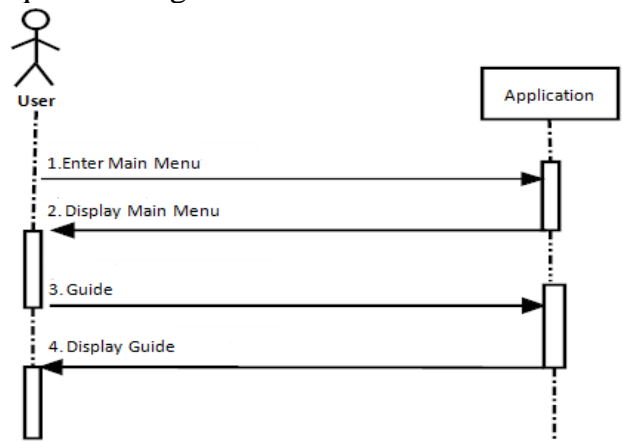

Figure 10. Sequence Diagram of Guide

Sequence Diagram above is the process that will be happen when the user choose Guide from the main menu and then the application will display Guide menu.

3. Sequence Diagram of About

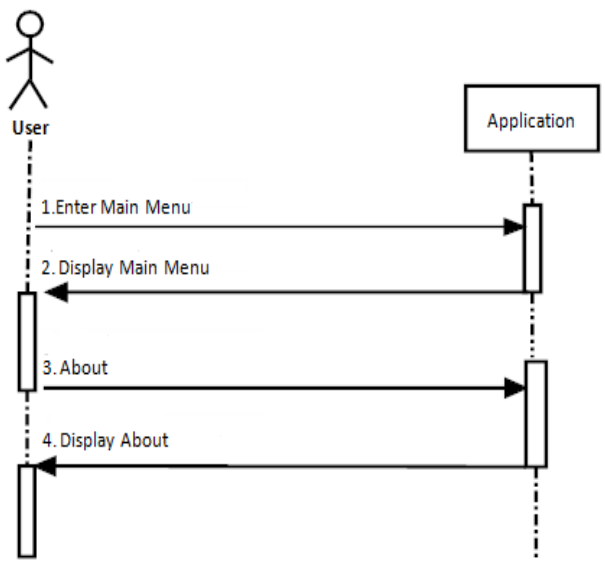

Figure 11. Sequence Diagram of About

Sequence Diagram above is the process that will be happen when the user choose About from the main menu and then the application will display About menu.

4. Sequence Diagram of Feedback 


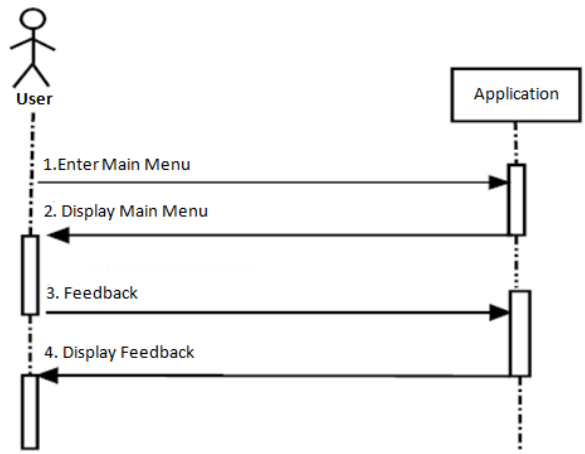

Figure 12. Sequence Diagram of Feedback

Sequence Diagram above is the process that will be happen when the user choose Feedback from the main menu and then the application will display Feedback menu.

5. Sequence Diagram of Quit

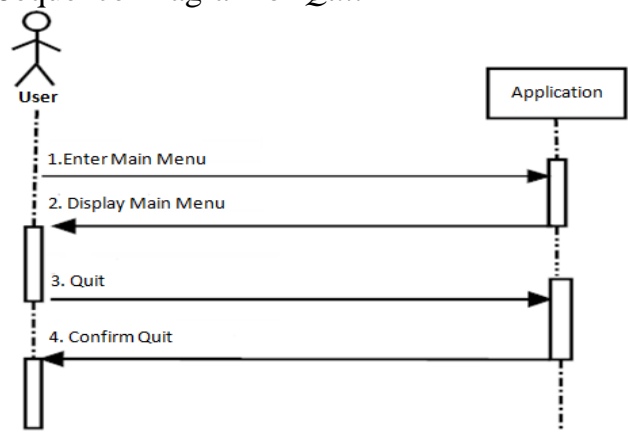

Figure 13. Sequence Diagram of Quit

Sequence Diagram above is the process that will be happen when the user choose Quit from the main menu and then the application will display Quit menu.

\section{Implementation and System Testing}

4.1 Application Implementation

Application implementation is the implementation of application on android based smartphone, and in this case the writers were trying to implement the application that had been made on Samsung Galaxy Grand Duos smartphone, and also try to explain how the program work by illustrating every displays accessed.

1. Display of Main Menu

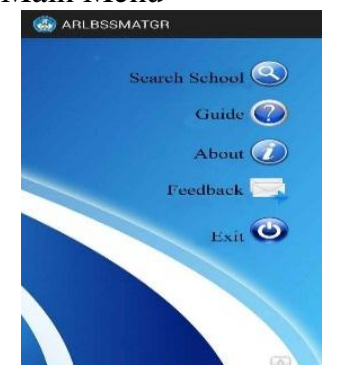

Figure 14. Main Menu

Figure 14 shows the main display of menu after Splash Screen displayed.

\section{Display of Search School}

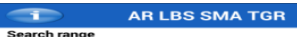

Showing spots within $10 \mathrm{~km}$

Figure 15. Search School

Figure 15 shows the display of Search School menu when the user chooses it from the main menu.

\section{Display of Guide}

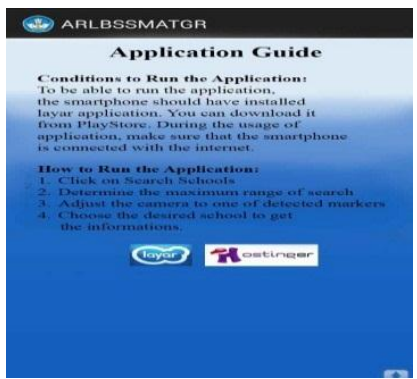

Figure 16. Search School

Figure 16 shows the display of Guide menu when the user chooses it from the main menu.

4. Display of About

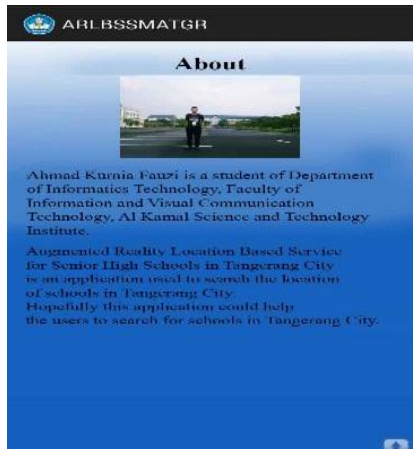

Figure 17. About

Figure 17 shows the display of About menu when the user chooses it from the main menu.

5. Display of Feedback

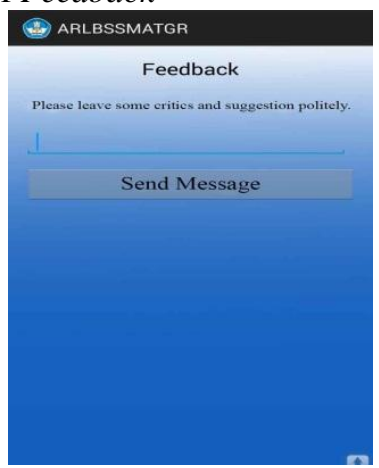

Figure 18. Feedback

Figure 18 shows the display of Feedback menu when the user chooses it from the main menu.

\subsection{Application Testing}


Application testing is an important part of application development. The tests were done to ensure the quality of product, and also to detect the weakness of software. In the process of testing, the writers tried to do the functional and accuration test on the application.

\subsubsection{Functional Testing}

Functional testing was the test of 13 processes in the application. After the tests, it was revealed that all of those 13 processes worked well.

\subsubsection{Accuration Testing}

Accuration testing was the test of 50 school data in the application. This test was done to know whether or not those 50 data are accurate, and after the tests it was revealed that all of those data are accurate.

\subsubsection{Questionnaire}

After the tests of application succeed, the last stage was to test the acceptance of user. To do that, the writers had conducted tests to 15 respondents by accidental sampling technique (Margono, 2007). In this technique, the respondents are common society. This was done to know if the application and its features is suitable for the user's need.

\section{Conclusion}

Based on the explanation that has been described, it can be concluded that the writers were succeeded to make an augmented reality location-based service application for senior high schools in Tangerang city using an android platform. The test results on some types of smartphone showed that this application could work well in any smartphone.

To use this application, the user needs internet connection and GPS. The challenge of using this application is this application needs a stable connection of internet and strong signal because it will affect on the time needed to prepare the contents of augmented reality.

Based on the questionnaire filled by 15 respondents and also application testings, this application got quite a good response from most respondents. From the calculation of questionnaire response, 68,09\% respondents very agree, 27,62\% agree, $1,43 \%$ disagree, and 2,86 very disagree with the use of this application. From that result, the total of very agree and agree reach $95,71 \%$ response of respondents.

\section{References}

[1] Fowler, M. 2004. UML Distilled. Yogyakarta: Andi.

[2] Jochen, S.\&Agnes Voisard. 2004. LocationBased Service. Berlin. Elsevier.

[3] Ladjamudin. 2005. Analisis dan Desain Sistem Informasi.Yogyakarta. Graha Ilmu.

[4] Milgram, Paul, Kishino, Fumio. 1994. Augmented Reality: A class of displays on the reality-virtuality continuum. Japan. ATR
Communication Systems Research Laboratories.

[5] Ronald Azuma. 1997. A Survey of Augmented Reality. Presence. Teleoperators Virtual Environments.

[6] Steiniger. 2006. Foundations of Location-based Services. Zurich. University of Zurich.

[7] Svennerberg, Gabriel. 2010. Begining Google Maps Api 3. New York. Apress. 